\title{
Persistent disabling breathlessness in chronic obstructive pulmonary disease
}

\author{
This article was published in the following Dove Press journal: \\ International Journal of COPD \\ 9 November 2016 \\ Number of times this article has been viewed
}

\author{
Josefin Sundh' \\ Magnus Ekström² \\ 'Department of Respiratory \\ Medicine, School of Medical Sciences, \\ Örebro University, Örebro, Sweden; \\ ${ }^{2}$ Department of Clinical Sciences, \\ Division of Respiratory Medicine \\ and Allergology, Lund University, \\ Lund, Sweden
}

\begin{abstract}
Objective: To determine the prevalence, change in breathlessness status over time, and risk factors for disabling and persistent disabling breathlessness in relation to treatments in chronic obstructive pulmonary disease (COPD).

Materials and methods: Longitudinal analysis of data from the Swedish National Register of COPD with breathlessness measured using modified Medical Research Council (mMRC) scores at two subsequent visits. Prevalence of disabling breathlessness ( $m M R C \geq 2$ at baseline) and persistent disabling breathlessness (disabling breathlessness at baseline and follow-up) was investigated in relation to COPD treatment. Risk factors for disabling breathlessness, change from non-disabling to disabling breathlessness, and persistent disabling breathlessness were analyzed using multiple logistic regression.

Results: A total of 1,689 patients were included in the study with a median follow-up of 12 months (interquartile range: 4 months). Prevalence of disabling breathlessness was 54\% at baseline. Persistent disabling breathlessness was present in $43 \%$ of patients despite treatment and in $74 \%$ of patients despite combined inhaled triple therapy and physiotherapy. Risk factors for disabling breathlessness or change to disabling breathlessness were higher age, lower lung function, frequent exacerbations, obesity, heart failure, depression, and hypoxic respiratory failure (all $P<0.05$ ). Persistent disabling breathlessness was associated with lower lung function and ischemic heart disease (all $P<0.05$ ).

Conclusion: Disabling breathlessness is common in COPD despite treatment, which calls for improved symptomatic treatments and consideration of factors influencing disabling breathlessness. Factors influencing disabling breathlessness should be considered for COPD management.
\end{abstract}

Keywords: COPD, breathlessness, dyspnea, longitudinal analysis, treatment, risk factors

\section{Introduction}

Breathlessness is a cardinal symptom in patients with chronic obstructive pulmonary disease (COPD). ${ }^{1,2}$ Breathlessness is measured using the modified Medical Research Council (mMRC) dyspnea scale, ${ }^{3}$ is strongly associated with impaired health-related quality of life, ${ }^{4,5}$ shorter survival,,${ }^{6,7}$ and predicts mortality even stronger than measures of health status ${ }^{7}$ and lung function ${ }^{6}$ in COPD. According to the current Global Initiative of Obstructive Lung Disease (GOLD) recommendations, breathlessness is an important factor for assessing disease severity and a major target for pharmacological and nonpharmacological treatment of COPD. ${ }^{1}$ Disabling breathlessness is commonly defined as an mMRC score of $\geq 2,{ }^{1}$ which means having breathlessness when walking slower than others or stopping when walking at own pace on level ground, stopping every $100 \mathrm{~m}$ or after a few minutes, or being too breathless to leave the house or being breathless on washing or dressing. An mMRC cut-off score of $\geq 2$ has been found to
Correspondence: Josefin Sundh Department of Respiratory Medicine, School of Medical Sciences, Örebro University, SE-70182, Örebro, Sweden Tel +46702349517

Fax +46 I9 186526

Email josefin.sundh@oru.se 
be optimal for prediction of increased mortality ${ }^{7}$ and is used in the current GOLD severity classification of COPD. ${ }^{1}$

Many patients have persistent disabling breathlessness despite optimal treatment of the underlying disease(s)..$^{8,9}$ Knowledge from real-life studies is limited on the prevalence, course, and risk factors for disabling breathlessness. In particular, the prevalence of persistent disabling breathlessness despite treatments for COPD in clinical practice is unknown. This information is important for management of COPD and for development of strategies to obtain relief from persistent disabling breathlessness.

The aim of this study was to determine the prevalence, change in breathlessness status over time, and risk factors associated with disabling and persistent breathlessness, particularly in relation to different treatment options for COPD.

\section{Materials and methods Study design and subjects}

This was a longitudinal analysis of the Swedish National Registry of COPD. ${ }^{10}$ The register was started in 2009 and is run on behalf of the Swedish Respiratory Society with governmental funding. Outpatient data are entered at patient visits in both primary care and hospital-based outpatient care, including patient demographics, lung function, health status (COPD Assessment Test), breathlessness (mMRC), smoking habits, exacerbations, treatments, and comorbid conditions. In the most recent annual report from 2015, the national coverage of all patients with severe and very severe COPD was valued to be $75 \% .{ }^{11}$ The calculation was based on a recent population-based study of prevalence of different COPD stages in Sweden. ${ }^{12}$

Inclusion criteria were a ratio of forced expiratory volume in one second to the forced expiratory volume $\left(\mathrm{FEV}_{1} / \mathrm{FVC}\right)$ below 0.7 , age 35 years and above, and having at least two registered visits (baseline and follow-up) separated by a minimum of 2 months during the period between January 1, 2013 and February 22, 2016.

\section{Methods}

The following data were obtained from the Swedish National Register of COPD: mMRC score, sex, age, smoking habits, spirometry data, body mass index (BMI), number of exacerbations, and hospitalizations due to exacerbations in the recent year, pharmacological or non-pharmacological treatment, and a doctor's diagnosis of comorbid heart failure, ischemic heart disease, depression, and hypoxemia. Generally, post-bronchodilator spirometry values were taken for the study, or if missing, pre-bronchodilator spirometry values were used.

Disabling breathlessness was defined as an mMRC score of $\geq 2$. Persistent disabling breathlessness was defined as disabling breathlessness at both baseline and follow-up (duration $\geq 2$ months). Frequent exacerbations were defined according to the GOLD criteria as having at least two exacerbations or one severe exacerbation leading to hospitalization in the recent year. ${ }^{1}$ Smoking was categorized as current daily smokers or nonsmokers. Lung function was measured by $\mathrm{FEV}_{1}$ as percentage of the predicted normal ( $\mathrm{FEV}_{1} \%$ pred), reported as mean $\mathrm{FEV}_{1}$ \% pred and GOLD stages I to IV, ${ }^{1}$ and analyzed as the effect of $10 \%$ change. Hypoxic respiratory failure was defined as oxygen saturation levels $\leq 88 \%{ }^{13}$ or use of long-term oxygen therapy (LTOT). COPD treatment groups included long-acting muscarinic antagonists (LAMA), long-acting beta-2-agonists (LABA), combined bronchodilators (LAMA + LABA), combined long-acting beta-2-agonists and inhalation corticosteroids (LABA + ICS), triple therapy (LAMA + LABA + ICS), per-oral steroids, LTOT, and physiotherapy (in recent 12 months). Maximal inhaled therapy was defined as inhaled triple therapy with LAMA, LABA, and ICS, and maximal treatment was defined as combined inhaled triple therapy and physiotherapy. Chronic breathlessness was defined as disabling breathlessness at both baseline and follow-up (duration $\geq 2$ months) despite triple inhaled therapy and physiotherapy.

\section{Analyses}

Differences in baseline characteristics between patients with or without disabling breathlessness were analyzed using cross-tabulations. The proportions of patients with persistent disabling breathlessness and those worsening from non-disabling to disabling breathlessness during follow-up were calculated. Persistent disabling breathlessness was investigated in the main population as well as within different COPD treatment groups.

Logistic regression with disabling breathlessness at follow-up as dependent variable and patient baseline characteristics as independent variables was performed. Sex, age, and all statistically significant factors from univariate analyses were included in the multivariate model.

Risk factors for persistent disabling breathlessness and change from non-disabling to disabling breathlessness over time were analyzed using conditional change multivariate logistic regression model with adjustment for breathlessness status at baseline (disabling or not) in addition to covariates from the main analysis. Almost all 
patients with hypoxic respiratory failure had disabling breathlessness status at baseline, and thus hypoxic respiratory failure could not be included in the conditional change model. All multiple logistic regression analyses were repeated with further adjustment for pharmacological and non-pharmacological treatments. A $P$-value below 0.05 was considered statistically significant. Statistical analyses were performed using SPSS version 22.0 (SPSS Inc, Chicago, IL, USA).

\section{Ethics}

The study protocol was approved by the Regional Ethical Review Board of Gothenburg (Dnr 393-15). Patients included in the National Register of COPD were informed verbally by the caregivers and by pamphlets and announcements at the clinics. Oral consents were received at inclusion from all patients who participated in the study. The Regional Ethical Review Board of Gothenburg did not require written informed consent to be obtained from the participants, because registration implied consent if not specifically expressed otherwise by the patients, and because the database used for analyses was anonymous to the authors of the study.

\section{Results \\ Population characteristics}

A total of 1,689 patients with mMRC scores at baseline and follow-up were included. The mean $\mathrm{FEV}_{1}$ \%pred was 51.3 among included patients and 53.8 among excluded patients without $\mathrm{mMRC}$ scores at both baseline and follow-up $(\mathrm{n}=817$; $P=0.001$ ). The patients had a mean age of 70 years, mean $\mathrm{FEV}_{1}$ of $51 \%$ of predicted ( $57 \%$ post-bronchodilator values and $43 \%$ pre-bronchodilator values), $27 \%$ of the patients were frequent exacerbators with either two exacerbations in total or one exacerbation requiring hospitalization in the recent year, and $53 \%$ were women. Patient characteristics by presence of disabling breathlessness are shown in Table 1. Lung function was stable over time, with mean $\mathrm{FEV}_{1}$ \%pred of 51.3 at baseline and 50.1 at follow-up.

\section{Prevalence and predictors of disabling breathlessness}

Disabling breathlessness was experienced by $54 \%$ of the patients at baseline. The distribution of mMRC scores is shown in Figure 1. The change of breathlessness status (disabling or not) from baseline to follow-up, during a

Table I Patient characteristics at baseline

\begin{tabular}{|c|c|c|c|}
\hline Patient characteristics at baseline & $\begin{array}{l}\text { All (mMRC 0-4) } \\
N=1,689(100 \%)\end{array}$ & $\begin{array}{l}\text { No disabling breathlessness } \\
(\mathrm{mMRC}<2) \text { at baseline } \\
\mathrm{N}=\mathbf{7 8 5}(\mathbf{4 7 \% )}\end{array}$ & $\begin{array}{l}\text { Disabling breathlessness } \\
(\mathrm{mMRC} \geq 2) \text { at baseline } \\
\mathrm{N}=894(53 \%)\end{array}$ \\
\hline \multicolumn{4}{|l|}{ Sex } \\
\hline Male, n (\%) & $795(47)$ & $364(46)$ & $431(48)$ \\
\hline Female, n (\%) & $894(53)$ & $42 I(54)$ & $473(52)$ \\
\hline Age (years), mean (SD) & $69.8(8.57)$ & $68.7(8.59)$ & $70.7(8.44)$ \\
\hline \multicolumn{4}{|l|}{ Current smokers (N=I,666), n (\%) } \\
\hline No & I, I86 (7I) & $507(65)$ & $679(76)$ \\
\hline Yes & $480(29)$ & $268(35)$ & $212(24)$ \\
\hline \multicolumn{4}{|l|}{ Body mass index $(\mathrm{N}=1,680), \mathrm{n}(\%)$} \\
\hline$<22.0$ & $357(21)$ & 145 (19) & $212(24)$ \\
\hline $22.0-29.9$ & $94 \mid(56)$ & $480(61)$ & $46 I(5 I)$ \\
\hline$\geq 30$ & $382(23)$ & $158(20)$ & $224(25)$ \\
\hline Body mass index, mean (SD) & $26.4(5.50)$ & $26.1(4.67)$ & $26.6(6.13)$ \\
\hline Frequent exacerbations, $\mathrm{n}(\%)$ & $307(18)$ & $62(8)$ & $245(27)$ \\
\hline FEV,\%pred, mean (SD) $(\mathrm{N}=\mathrm{I}, 635)$ & $51.3(17.0)$ & $58.4(\mid 4.7)$ & $44.8(16.4)$ \\
\hline \multicolumn{4}{|l|}{ COPD stage $(\mathrm{N}=1,635), \mathrm{n}(\%)$} \\
\hline I & $75(5)$ & $56(7)$ & $19(2)$ \\
\hline II & $781(48)$ & $495(64)$ & $286(33)$ \\
\hline III & $599(36)$ & $206(27)$ & $393(46)$ \\
\hline IV & $180(11)$ & $17(2)$ & $163(19)$ \\
\hline Heart failure, n (\%) & $82(5)$ & $18(2)$ & $64(7)$ \\
\hline Ischemic heart disease, $\mathrm{n}(\%)$ & $182(I \mid)$ & $77(10)$ & $105(12)$ \\
\hline Depression, n (\%) & $185(11)$ & $60(8)$ & $125(14)$ \\
\hline Hypoxic respiratory failure, n (\%) & $32(2)$ & I (0) & $31(3)$ \\
\hline
\end{tabular}

Notes: Results from cross-tabulations of the baseline population ( $\mathrm{N}=1,689$, median time between visits: 12 months [IQR 4 months]).

Abbreviations: COPD, chronic obstructive pulmonary disease; FEV \%pred, forced expiratory volume in one second in percentage of predicted; IQR, interquartile range; mMRC, modified Medical Research Council; SD, standard deviation. 


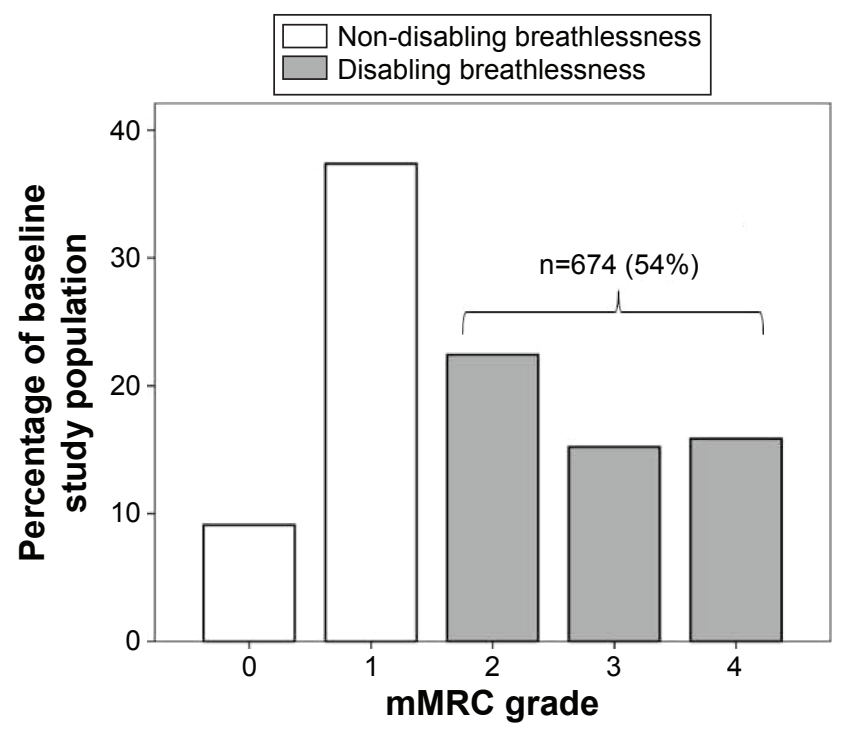

Figure I Distribution of mMRC grades in the baseline COPD population. Note: Percentages of patients with different mMRC grades in the baseline population $(n=1,689)$.

Abbreviations: COPD, chronic obstructive pulmonary disease; mMRC, modified Medical Research Council.

median time of 12 (interquartile range: 4) months, is shown in Figure 2. In longitudinal univariate logistic regression analyses, disabling breathlessness at follow-up was more common in patients with higher age, frequent exacerbations, obesity, heart failure, ischemic heart disease, depression, or hypoxic respiratory failure. Disabling breathlessness was less common with increasing $\mathrm{FEV}_{1}$ \%pred and in current smokers (Table 2). All patients, but one, with hypoxic respiratory failure had disabling breathlessness. In multivariate analysis, disabling breathlessness was more common with higher age, decreasing $\mathrm{FEV}_{1}$ \%pred, and in patients with frequent exacerbations, obesity, heart failure, depression, and hypoxic respiratory failure (Table 2). The results did not substantially change after further adjustment for groups

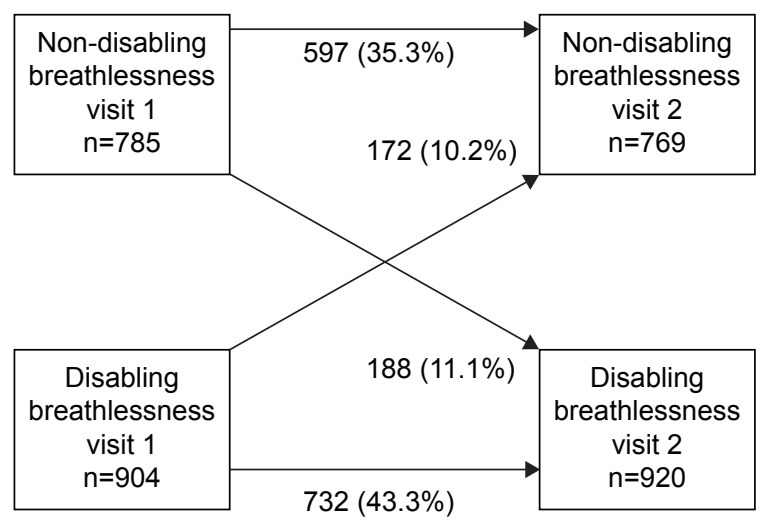

Figure 2 Change in breathlessness status over time $(n=1,689)$.
Table 2 Risk factors for disabling breathlessness in longitudinal analyses

\begin{tabular}{|c|c|c|}
\hline \multirow[t]{2}{*}{ Variables at baseline } & \multicolumn{2}{|c|}{$\begin{array}{l}\text { Disabling breathlessness } \\
\text { at follow-up }\end{array}$} \\
\hline & $\begin{array}{l}\text { Univariate } \\
\text { analysis } \\
\text { OR }(95 \% \mathrm{CI})\end{array}$ & $\begin{array}{l}\text { Multivariate } \\
\text { analysis } \\
\text { OR }(95 \% \mathrm{CI})\end{array}$ \\
\hline Female sex & $1.02(0.84-1.24)$ & $0.98(0.78-1.23)$ \\
\hline Age (effect of I0 years difference) & $1.43(1.27-1.61)$ & $1.38(1.20-1.58)$ \\
\hline FEV,$\%$ pred (effect of I0\% change) & $0.58(0.54-0.62)$ & $0.60(0.55-0.64)$ \\
\hline Current smokers & $0.57(0.46-0.7 \mathrm{I})$ & $0.86(0.66-1.11)$ \\
\hline Frequent exacerbations & $3.21(2.39-4.29)$ & $1.81(1.30-2.52)$ \\
\hline \multicolumn{3}{|l|}{ Body mass index } \\
\hline$<22.0$ & $1.23(0.95-1.57)$ & $0.86(0.64-1.16)$ \\
\hline \multicolumn{3}{|l|}{$22.0-29.9$} \\
\hline$\geq 30$ & $1.32(1.03-1.68)$ & $1.36(1.03-1.79)$ \\
\hline Heart failure & $4.09(2.27-7.35)$ & $2.42(1.23-4.74)$ \\
\hline Ischemic heart disease & $1.81(1.20-2.52)$ & $1.44(0.98-2.11)$ \\
\hline Depression & $1.99(1.42-2.79)$ & $2.05(1.40-3.02)$ \\
\hline Hypoxic respiratory failure & $23.0(3.11-169.6)$ & $7.83(1.02-60.0)$ \\
\hline
\end{tabular}

Notes: Univariate and multivariate longitudinal analyses of disabling breathlessness at follow-up with independent variables at baseline $(n=1,607)$. Disabling breathlessness $=$ mMRC $\geq 2$. Median follow-up time $=12$ (IQR: 4) months.

Abbreviations: $\mathrm{Cl}$, confidence interval; $\mathrm{COPD}$, chronic obstructive pulmonary disease; $\mathrm{FEV}, \%$ pred, forced expiratory volume in one second in percentage of predicted; IQR, interquartile range; OR, odds ratio; mMRC, modified Medical Research Council.

receiving pharmacological treatment and physiotherapy (data not shown).

\section{Change in breathlessness over time}

The prevalence of persistent disabling breathlessness at follow-up according to COPD treatments at baseline is shown in Table 3 and Figure 3. More intense COPD treatment was driven by higher breathlessness. The prevalence of

Table 3 Persistent disabling breathlessness despite COPD treatment

\begin{tabular}{lll}
\hline $\begin{array}{l}\text { Maintenance } \\
\text { treatment at } \\
\text { baseline }\end{array}$ & $\begin{array}{l}\text { Number of } \\
\text { patients } \\
(\mathbf{N}=\mathbf{I , 6 8 9 )}\end{array}$ & $\begin{array}{l}\text { Patients with } \\
\text { persistent disabling } \\
\text { breathlessness, } \mathbf{n}(\%)\end{array}$ \\
\hline LABA only & 35 & $8(23)$ \\
LAMA only & 214 & $61(29)$ \\
LABA + ICS & 170 & $64(38)$ \\
LAMA + LABA only & 74 & $37(50)$ \\
LABA + LAMA + ICS & 771 & $436(57)$ \\
Physiotherapy & 330 & $226(69)$ \\
Per-oral steroids & $4 I$ & $30(73)$ \\
LTOT & 22 & $21(96)$ \\
Physiotherapy + & 211 & $155(74)$ \\
LABA + LAMA + ICS & &
\end{tabular}

Note: Data on total number of patients with maintenance treatment, with row percentages showing proportions of patients with persistent disabling breathlessness within each treatment group.

Abbreviations: COPD, chronic obstructive pulmonary disease; LAMA, longacting muscarinic antagonists; LABA, long-acting beta-2-agonists; ICS, inhalation corticosteroids; LTOT, long-term oxygen therapy. 


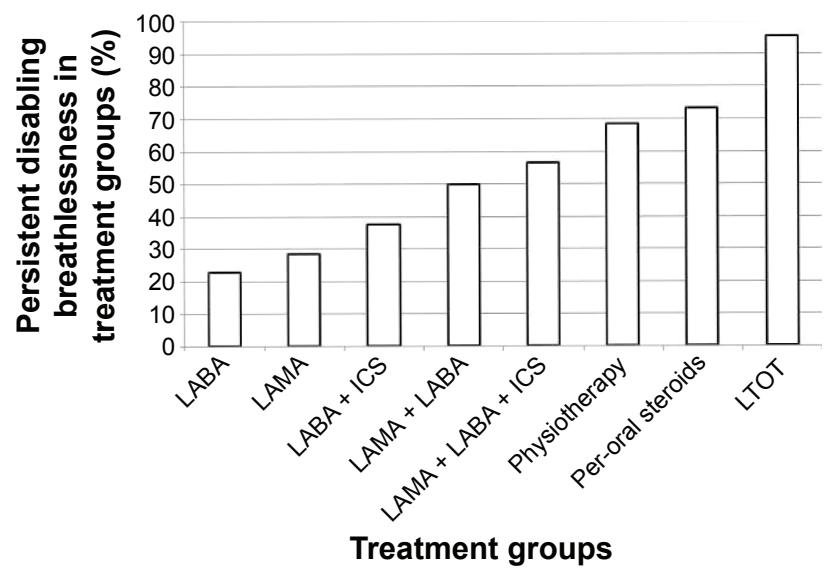

Figure 3 Persistent disabling breathlessness (PDB) in treatment groups. Note: Data presented as percentages of PDB in different treatment groups $(n=1,689)$.

Abbreviations: LAMA, long-acting muscarinic antagonists; LABA, long-acting beta2-agonists; ICS, inhalation corticosteroids; LTOT, long-term oxygen therapy.

persistent disabling breathlessness increased from about $20 \%$ in patients on a single long-acting bronchodilator to $>50 \%$ in patients with two long-acting bronchodilators and/or ICS, and was even higher in patients with per-oral steroids and LTOT (Figure 3). Chronic breathlessness (persistent disabling breathlessness despite inhaled triple therapy and physiotherapy) was present in $74 \%$ of patients (Table 3 ). Among patients with persistent disabling breathlessness, $40 \%$ had not received maximal inhaled triple therapy and $69 \%$ had not received physiotherapy (Figure 4), and as many as $79 \%$ had not been prescribed the maximal combination of inhaled triple therapy and physiotherapy.

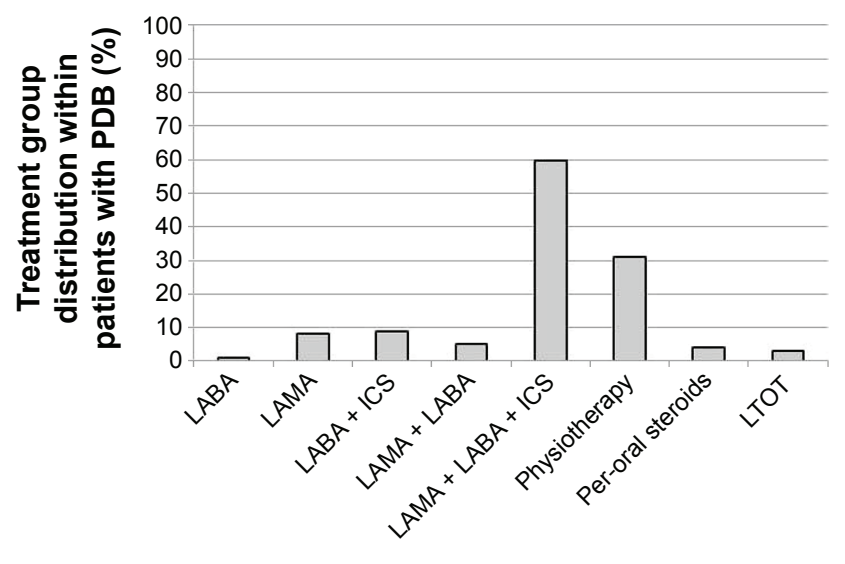

\section{Treatment groups}

Figure 4 Distribution of treatment groups within patients with persistent disabling breathlessness (PDB).

Note: Data presented as percentages of patients in different treatment groups with PDB ( $n=732)$.

Abbreviations: LAMA, long-acting muscarinic antagonists; LABA, long-acting beta-2agonists; ICS, inhalation corticosteroids; LTOT, long-term oxygen therapy.
Table 4 Risk factors for change in disabling breathlessness over time

\begin{tabular}{|c|c|c|}
\hline Variables at baseline & $\begin{array}{l}\text { Worsening } \\
\text { to disabling } \\
\text { breathlessness }\end{array}$ & $\begin{array}{l}\text { Persistent } \\
\text { disabling } \\
\text { breathlessness }\end{array}$ \\
\hline Female sex & I.0I (0.7I-I.44) & $1.19(0.83-1.72)$ \\
\hline Age (effect of 10 years difference) & $1.44(1.14-1.81)$ & $1.15(0.93-1.44)$ \\
\hline FEV $\%$ pred (effect of $10 \%$ change) & $0.71(0.62-0.80)$ & $0.67(0.60-0.75)$ \\
\hline Current smokers & $0.84(0.56-1.25)$ & $0.93(0.60-1.43)$ \\
\hline Frequent exacerbations & $1.19(0.63-2.23)$ & $1.27(0.79-2.04)$ \\
\hline \multicolumn{3}{|l|}{ Body mass index } \\
\hline$<22.0$ & $0.89(0.55-1.43)$ & $0.67(0.42-1.08)$ \\
\hline \multicolumn{3}{|l|}{$22.0-29.9$} \\
\hline$\geq 30$ & $1.27(0.82-1.97)$ & $0.98(0.63-1.52)$ \\
\hline Heart failure & $2.13(0.73-6.20)$ & $1.85(0.67-5.11)$ \\
\hline Ischemic heart disease & $1.38(0.79-2.41)$ & $2.28(1.09-4.75)$ \\
\hline Depression & $2.27(1.25-4.09)$ & $1.29(0.72-2.30)$ \\
\hline
\end{tabular}

Notes: Results from multivariate logistic regression in conditional change model with worsening and persistent disabling breathlessness as dependent variables $(n=1,607)$. Median follow-up time =12 (IQR: 4) months. Persistent disabling breathlessness = $m M R C \geq 2$ at baseline and follow-up.

Abbreviations: $\mathrm{FEV}, \%$ pred, forced expiratory volume in one second in percentage of predicted; IQR, interquartile range; mMRC, modified Medical Research Council.

\section{Predictors of persistent disabling breathlessness and worsening over time}

The presence of persistent disabling breathlessness was predicted by lower $\mathrm{FEV}_{1}$ \%pred and was about twice as likely in patients with ischemic heart disease (Table 4). Predictors of developing disabling breathlessness over time were higher age, lower $\mathrm{FEV}_{1}$ \%pred, frequent exacerbations, obesity, and comorbid depression (Table 4). The results did not substantially change after further adjustment for groups receiving pharmacological treatment and physiotherapy (data not shown).

\section{Discussion \\ Main findings}

The first finding is that disabling breathlessness is common in COPD patients despite treatment. The risk of disabling breathlessness over a median of 12 months was higher in patients with higher age, lower $\mathrm{FEV}_{1}$ \%pred, frequent exacerbations, obesity, heart failure, depression, and hypoxic respiratory failure.

The second important finding is that most patients remained in the same status of breathlessness over time, with almost half of the patients having persistent disabling breathlessness.

Third, although some patients with persistent disabling breathlessness were not maximally treated, the majority of patients had chronic breathlessness, ie, persistent disabling breathlessness despite intensive COPD treatment including triple inhaled therapy and physiotherapy. 


\section{What does this study add?}

The major novelty of this study is that it includes longitudinal analyses of predictors of disabling breathlessness, change in breathlessness status over time, and persistent disabling breathlessness related to therapy.

In previous studies, the prevalence of disabling breathlessness with $\mathrm{mMRC} \geq 2$ has differed from $39.5 \%$ to $60.2 \%$ in different European countries, so the proportion found in this study is consistent with international findings. ${ }^{14}$ Previous studies of associations with breathlessness have mainly been cross-sectional analyses, with findings of associations with higher age,${ }^{15}$ lower lung function, ${ }^{15,16}$ frequent exacerbations, ${ }^{15,16}$ comorbid underweight, ${ }^{17,18}$ obesity, ${ }^{15,16,19,20}$ heart failure, ${ }^{16}$ and depression..$^{16}$ The importance of depression as a risk factor for breathlessness, rather than the reverse that breathlessness causes depression and anxiety, has been shown and discussed previously, ${ }^{21}$ and is confirmed in the present study. However, this study shows that age, $\mathrm{FEV}_{1}$ \%pred, exacerbations, obesity, and heart failure are associated with disabling breathlessness even in a longitudinal analysis, and these data are important as they indicate a causal relation. It is speculated that the association of hypoxic respiratory failure with disabling breathlessness is mainly a marker for more severe disease, but hypoxemia could also potentially be associated with increased ventilatory drive in some patients.

As for the analyses of change in breathlessness status, it is previously known that the mean mMRC score worsens over time, ${ }^{22,23}$ but this study also distinguishes different courses over time and adds analyses of persistent disabling breathlessness in relation to treatment alternatives. As for the analysis of persistent disabling breathlessness, it is speculated that the association of ischemic heart disease with persistent disabling breathlessness may indicate that treatment of ischemic heart disease has not been paid attention to the same extent as comorbid heart failure, and that optimized treatment of comorbid heart disease is a potential way to decrease the disability from breathlessness in COPD. The conclusion is that treatment of comorbid diseases, which themselves cause breathlessness, is very important for COPD patients.

As breathlessness is a major symptom and cause of disability in COPD, symptomatic management is of utter importance to improve symptom control, mastery, and quality of life in patients with persistent disabling breathlessness. The need for focusing clinical management and research on chronic breathlessness, a syndrome that impacts the patients' function or well-being despite maximal treatment for the underlying disease, has recently been pointed out. ${ }^{24,25}$
There is good evidence for reducing breathlessness by both pharmacological treatment with bronchodilators ${ }^{26,27}$ and by physical training, ${ }^{28}$ and the importance of a symptom-based therapy has recently been proposed. ${ }^{29}$ This study confirms the results from a Spanish study where breathlessness was an important determinant for stepping up treatment. ${ }^{30}$ The clear association of disabling breathlessness with more advanced treatment could partly be explained by treatment choice, being based on symptoms as well as lung function and exacerbation frequency. ${ }^{1}$ However, patients with disabling breathlessness may also consult their doctors more often and subsequently receive more advanced treatments. However, there is obviously a room for improvement in COPD management, as not all patients with disabling breathlessness received maximal treatment. Unfortunately, physiotherapy in the recent 12 months was even less common than pharmacological therapy. Swedish national guidelines and treatment recommendations did not include the GOLD ABCD classification until 2015, which means that previous pharmacological treatments could have been more guided by lung function stage than by grade of breathlessness. However, even more interesting is that a high proportion of patients had chronic breathlessness despite intensive COPD treatment, with $74 \%$ of patients receiving both inhaled triple therapy and physiotherapy. This is an important finding which indicates that available treatments are insufficient and that improved management strategies for symptom relief are needed.

\section{Strengths and limitations}

The major strengths of this study are the national multi-center design and that analyses of breathlessness were multivariate, longitudinal, and investigated persistent disabling breathlessness related to COPD therapy. The study uses real-life data from clinical practice in both primary and secondary care, which should ensure a good external validity. The prevalence of disabling breathlessness correspond well to an average of mMRC scores in COPD patients in five different European countries. ${ }^{14}$ In the same study, the mean age was slightly lower than in this study and the majority of patients were men, but in another large primary care database in UK, ${ }^{31}$ the mean age and proportion of men were similar to this study. In addition, the sex and age distribution of this study is consistent with other Swedish observational COPD studies, with either primary ${ }^{32}$ or secondary ${ }^{33}$ COPD patients, and in a regional observational database with patients from both primary and secondary care. ${ }^{34}$ Therefore, the generalizability of the study findings is likely to be good. 
Important limitations were that no data on treatment of comorbidity and symptomatic treatment with opioids or benzodiazepines was included. Previous meta-analyses have shown that opioids but not benzodiazepines are effective as symptomatic treatment for breathlessness, and information on the impact of opioids would have been of great interest for the analyses. ${ }^{35,36}$ Breathlessness in COPD patients may be influenced by comorbid conditions. The analyses were adjusted for comorbid heart failure and ischemic heart disease, but lacked more detailed information on parameters such as left ventricular ejection fractions, pulmonary hypertension, and hemoglobulin levels. Furthermore, data registration was not complete for all variables. However, according to the most recent annual report from the register, the national coverage of severe and very severe COPD is acceptable. ${ }^{11}$ Another issue is that the exact durations of medical treatment are unknown, but as reported treatment was prescribed at the latest at visit 1 and the follow-up time was minimum 2 months; it is reasonable to believe that a treatment effect on breathlessness should have been achieved. Finally, the attrition analysis showed that the included patients had statistically significant lower lung function than the patients excluded due to the absence of baseline and follow-up data on mMRC, however it is believed that the difference was not clinically significant.

\section{Implications}

The most important implications of this study are that persistent disabling breathlessness is common, and that although many patients do not have maximal COPD treatment, there is a considerable proportion of patients having chronic breathlessness despite maximal treatment. Several factors influencing disabling breathlessness, such as comorbid conditions and their treatment, should be considered and optimized for COPD management.

Important research implications are that future studies of breathlessness in COPD should include persistent breathlessness as this state is an important clinical problem in COPD, and also consider treatment of comorbid conditions. As COPD is an irreversible disease, future clinical management and research need to focus on symptomatic treatment.

\section{Conclusion}

Disabling breathlessness is influenced by age, $\mathrm{FEV}_{1} \%$ pred, exacerbations, and several comorbid conditions, which should be considered in managing COPD. Persistent disabling breathlessness is common despite treatment, which calls for development of new treatment options and strategies for symptom relief in COPD.

\section{Acknowledgments}

The authors thank the National Register of COPD for supplying data to the study. The study was supported by the Region Örebro County through funding by ALF (Avtal om Läkarutbildning och Forskning [Agreement concerning Cooperation on Medical Education and Research]).

\section{Disclosure}

The authors report no conflicts of interest in this work.

\section{References}

1. Global Initiative for Chronic Obstructive Lung Disease. Global strategy for the diagnosis, management, and prevention of chronic obstructive pulmonary disease. Available from: http://www.goldcopd.com. Accessed June 14, 2016.

2. Miravitlles M, Ferrer J, Baro E, Lleonart M, Galera J. Differences between physician and patient in the perception of symptoms and their severity in COPD. Respir Med. 2013;107(12):1977-1985.

3. Mahler DA, Wells CK. Evaluation of clinical methods for rating dyspnea. Chest. 1988;93(3):580-586.

4. Bestall JC, Paul EA, Garrod R, Garnham R, Jones PW, Wedzicha JA. Usefulness of the Medical Research Council (MRC) dyspnoea scale as a measure of disability in patients with chronic obstructive pulmonary disease. Thorax. 1999;54(7):581-586.

5. Wilke S, Jones PW, Mullerova H, et al. One-year change in health status and subsequent outcomes in COPD. Thorax. 2015;70(5):420-425.

6. Nishimura K, Izumi T, Tsukino M, Oga T. Dyspnea is a better predictor of 5-year survival than airway obstruction in patients with COPD. Chest. 2002;121(5):1434-1440.

7. Casanova C, Marin JM, Martinez-Gonzalez C, et al. Differential effect of modified Medical Research Council Dyspnea, COPD Assessment Test, and Clinical COPD Questionnaire for symptoms evaluation within the new GOLD staging and mortality in COPD. Chest. 2015;148(1):159-168.

8. Parshall MB, Schwartzstein RM, Adams L, et al. An official American Thoracic Society statement: update on the mechanisms, assessment, and management of dyspnea. Am J Respir Crit Care Med. 2012;185(4):435-452.

9. Johnson MJ, Currow DC. Chronic refractory breathlessness is a distinct clinical syndrome. Curr Opin Support Palliat Care. 2015;9(3):203-205.

10. Henoch I, Strang S, Löfdahl C-G, Ekberg-Janssn A. Health-related quality of life in a nationwide cohort of patients with COPD related to other characteristics. Eur Clin Respir J. 2016;3:31459.

11. Luftvägsregistret, Årsrapport 2015 [Swedish National Register of COPD, Annual report 2015]. Available from: http://www.registercentrum.se/sites/default/files/dokument/luftvagsregistret_arsrapport_2015. pdf. Accessed October 30, 2016.

12. Backman H, Eriksson B, Ronmark E, et al. Decreased prevalence of moderate to severe COPD over 15 years in northern Sweden. Respir Med. 2016;114:103-110.

13. Qaseem A, Wilt TJ, Weinberger SE, et al. Diagnosis and management of stable chronic obstructive pulmonary disease: a clinical practice guideline update from the American College of Physicians, American College of Chest Physicians, American Thoracic Society, and European Respiratory Society. Ann Intern Med. 2011;155(3):179-191.

14. Punekar YS MH, Small M, Holbrook T, Wood R, Naya I, Valle M. Prevalence and burden of dyspnoea among patients with chronic obstructive pulmonary disease in five European countries. Pulm Ther. 2016;2:59-72. 
15. Mullerova H, Lu C, Li H, Tabberer M. Prevalence and burden of breathlessness in patients with chronic obstructive pulmonary disease managed in primary care. PloS One. 2014;9(1):e85540.

16. Perez T, Burgel PR, Paillasseur JL, et al. Modified Medical Research Council scale vs Baseline Dyspnea Index to evaluate dyspnea in chronic obstructive pulmonary disease. Int J Chron Obstruct Pulmon Dis. 2015; 10:1663-1672.

17. Katsura H, Yamada K, Kida K. Both generic and disease specific healthrelated quality of life are deteriorated in patients with underweight COPD. Respir Med. 2005;99(5):624-630.

18. Sahebjami H, Sathianpitayakul E. Influence of body weight on the severity of dyspnea in chronic obstructive pulmonary disease. Am J Respir Crit Care Med. 2000;161(3 Pt 1):886-890.

19. Launois C, Barbe C, Bertin E, et al. The modified Medical Research Council scale for the assessment of dyspnea in daily living in obesity: a pilot study. BMC Pulm Med. 2012;12:61.

20. Garcia-Rio F, Soriano JB, Miravitlles M, et al. Impact of obesity on the clinical profile of a population-based sample with chronic obstructive pulmonary disease. PloS One. 2014;9(8):e105220.

21. Neuman A, Gunnbjornsdottir M, Tunsater A, et al. Dyspnea in relation to symptoms of anxiety and depression: a prospective population study. Respir Medicine. 2006;100(10):1843-1849.

22. Oga T, Nishimura K, Tsukino M, Sato S, Hajiro T, Mishima M. Longitudinal deteriorations in patient reported outcomes in patients with COPD. Respir Med. 2007;101(1):146-153.

23. Oga T, Tsukino M, Hajiro T, Ikeda A, Nishimura K. Analysis of longitudinal changes in dyspnea of patients with chronic obstructive pulmonary disease: an observational study. Respir Res. 2012;13(1):85.

24. Currow DC, Abernethy AP, Allcroft P, et al. The need to research refractory breathlessness. Eur Respir J. 2016;47(1):342-343.

25. Currow DC, Johnson MJ. Chronic breathlessness: silent and deadly. Curr Opin Support Palliat Care. 2016;10(3):221-222.

26. Karner C, Chong J, Poole P. Tiotropium versus placebo for chronic obstructive pulmonary disease. Cochrane Database Syst Rev. 2014;7: CD009285.

27. Kew KM, Mavergames C, Walters JA. Long-acting beta2-agonists for chronic obstructive pulmonary disease. Cochrane Database Syst Rev. 2013;10:CD010177.
28. McCarthy B, Casey D, Devane D, Murphy K, Murphy E, Lacasse Y. Pulmonary rehabilitation for chronic obstructive pulmonary disease. Cochrane Database Syst Rev. 2015;2:CD003793.

29. Cabrera C, Casanova C, Martin Y, et al. Agreement between a simple dyspnea-guided treatment algorithm for stable COPD and the GOLD guidelines: a pilot study. Int J Chron Obstruct Pulmon Dis. 2016;11: 1217-1222.

30. Lopez-Campos JL, Abad Arranz M, Calero Acuna C, et al. Determinants for changing the treatment of COPD: a regression analysis from a clinical audit. Int J Chron Obstruct Pulmon Dis. 2016;11:1171-1178.

31. Jones RC, Price D, Chavaness NH, et al. Multi-component assessment of chronic obstructive pulmonary disease: an evaluation of the ADO and DOSE indices and the global obstructive lung disease categories in international primary care data sets. NPJ Prim Care Respir Med. 2016; 26:16010.

32. Stallberg B, Janson C, Johansson G, et al. Management, morbidity and mortality of COPD during an 11-year period: an observational retrospective epidemiological register study in Sweden (PATHOS). Prim Care Respir J. 2014;23(1):38-45.

33. Sundh J, Johansson G, Larsson K, et al. Comorbidity and health-related quality of life in patients with severe chronic obstructive pulmonary disease attending Swedish secondary care units. Int J Chron Obstruct Pulmon Dis. 2015;10:173-183.

34. Sundh J, Stallberg B, Lisspers K, Kampe M, Janson C, Montgomery S. Comparison of the COPD Assessment Test (CAT) and the Clinical COPD Questionnaire (CCQ) in a clinical population. COPD. 2015:1-9.

35. Ekstrom M, Nilsson F, Abernethy AA, Currow DC. Effects of opioids on breathlessness and exercise capacity in chronic obstructive pulmonary disease. A systematic review. Ann Am Thorac Soc. 2015;12(7): 1079-1092.

36. Simon ST, Higginson IJ, Booth S, Harding R, Bausewein C. Benzodiazepines for the relief of breathlessness in advanced malignant and non-malignant diseases in adults. Cochrane Database System Rev. 2010(1):CD007354
International Journal of COPD

\section{Publish your work in this journal}

The International Journal of COPD is an international, peer-reviewed journal of therapeutics and pharmacology focusing on concise rapid reporting of clinical studies and reviews in COPD. Special focus is given to the pathophysiological processes underlying the disease, intervention programs, patient focused education, and self management protocols.

\section{Dovepress}

This journal is indexed on PubMed Central, MedLine and CAS. The manuscript management system is completely online and includes a very quick and fair peer-review system, which is all easy to use. Visit http://www.dovepress.com/testimonials.php to read real quotes from published authors. 